\title{
LA-UR-21-21128
}

Approved for public release; distribution is unlimited.

Title: $\quad$ Plutonium workers get a new level of education in the actinide mission

Author(s): $\quad$ Lunn, Maureen Elizabeth

Intended for: Web

Issued: $\quad$ 2021-02-08 
Disclaimer:

Los Alamos National Laboratory, an affirmative action/equal opportunity employer, is operated by Triad National Security, LLC for the National Nuclear Security Administration of U.S. Department of Energy under contract 89233218CNA000001. By approving this article, the publisher recognizes that the U.S. Government retains nonexclusive, royalty-free license to publish or reproduce the published form of this contribution, or to allow others to do so, for U.S. Government purposes. Los Alamos National Laboratory requests that the publisher identify this article as work performed under the auspices of the U.S. Department of Energy. Los Alamos National Laboratory strongly supports academic freedom and a researcher's right to publish; as an institution, however, the Laboratory does not endorse the viewpoint of a publication or guarantee its technical correctness. 


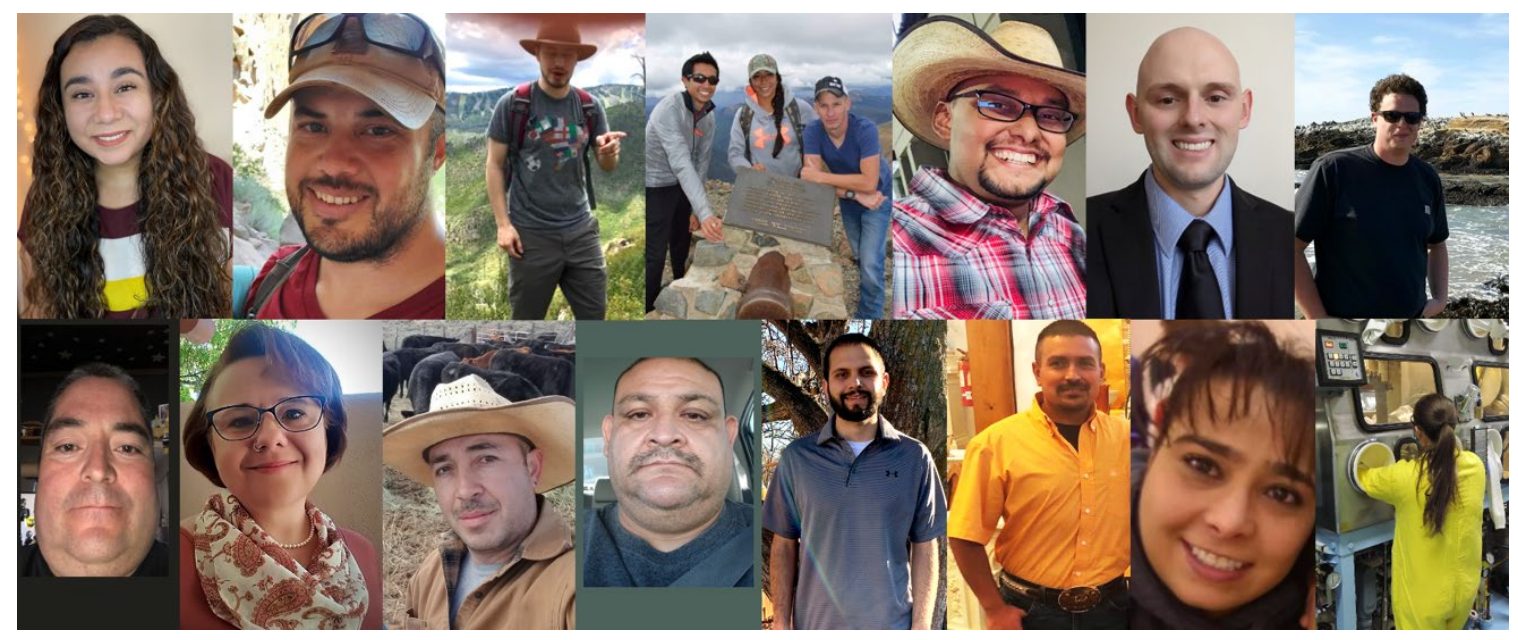

The first cohort of the new Nuclear Enterprise Science and Technology certificate program.

Upper row: Kimberly Bonilla (C-AAC), Joel Christensen (AMPP-4), Patrick Fisher (SI-DCRM), Garrett Fulcher (AMPP-4) (right), Miguel Rodriguez (AMPP-3), Tyler Kukucha (NPI-6), Alexander Lloyd (PT-3)

Lower row: Felix Mascarenas (NPI-6), Helen Milenski (MST-16), James Montoya (NPI-9), Victor Jaramillo (NPI-6) Donevon Sanchez (TA55-WF), Eugene Sandoval (ORI-1), Tatum Terrazas (NPI-9), Rachael Ward (NPI-9)

The Associate Laboratory Directorate for Weapons Production (ALDWP) and the National Security Education Center (NSEC) have teamed to develop a new Nuclear Enterprise Science and Technology (NEST) Academic Certificate program offered through the University of New Mexico - Los Alamos (UNM-LA). The pilot program, which virtually kicked off on January 19 even amidst snow closures, received accreditation by the State Higher Education Department (HED) in FY20 and is designed for LANL's existing fissile material handler technician and technologist employee workforce. It will provide essential science, operations, and business education on all aspects of working in modern nuclear materials handling and processing facilities. The first course for the certificate program is called "Nuclear Facility Fundamentals." A call for nominations went out to the directorate and a cohort of 15 individuals has been established to start the program.

NEST will address all aspects of working with plutonium (and other related special nuclear materials) for the next generation of technicians, operators, scientists and engineers to establish an effective and safe operating culture. The content will address specialized operational and technological aspects relevant to the actinide science mission. The program will also support the transformation of a UNM-LA building into a hands-on glovebox laboratory, where students can practice working in the containers that protect employees from hazardous materials.

Marianne Wilkerson (C-DO), a UNM/LANL Joint Appointee, is the instructor for Nuclear Facility Fundamentals, the first course offered through UNM-LA for the NEST Certificate Program. Wilkerson began her career at LANL as an undergraduate student in INC-4 and then completed her Ph.D. thesis research in inorganic chemistry with Carol Burns (DDSTE) and Robert Paine at UNM-Albuquerque, and her post-doctoral work with Harry Dewey (C-ADI). In addition to her duties for the NEST program, Wilkerson has served as Principal Investigator for a number of projects in nuclear forensics and plutonium science. For this first course, she has engaged LANL subject matter experts to deliver specific units on our historical background (Alan Carr (WRS-SIS)), interactions of radiation with matter (John Klumpp (RP-SVS)), nuclear material control and accountability (Katrina Koehler (NEN-1)), and criticality (Mandy Bowles-Tomaszewski (NCS) and Norann Calhoun (NCS)).

"I am extremely impressed with each member of our first cohort," says Wilkerson. "As a class, they contribute considerable work experience and technical knowledge to both the course and the new Certificate program, and all are excited to learn together. I am truly honored with this opportunity to support their academic goals and technical careers." 
The program will serve as a new level of foundational education for plutonium workers in support of the national security mission. Congratulations to the members of the first NEST cohort!

\section{For Social Media}

- Group photo

- Caption: Recently 15 employees added 'student' to their list of duties, as they began the new Nuclear Enterprise Science and Technology (NEST) Academic Certificate program offered through the University of New Mexico - Los Alamos. 